Original article

\title{
SPECIES COMPOSITION OF TRICHINELLA IN DOMESTIC AND WILD ANIMALS IN BULGARIA
}

\author{
N. LALKOVSKI \\ National Diagnostic and Research Veterinary Medical Institute, Sofia, Bulgaria
}

\begin{abstract}
Summary
Lalkovski, N., 2019. Species composition of Trichinella in domestic and wild animals in Bulgaria. Bulg. J. Vet. Med., 22, No 1, 99-104.

Four Trichinella species cause trichinellosis in Europe: Trichinella spiralis, Trichinella britovi, Trichinella nativa and Trichinella pseudospiralis. The aim of our study was to determine the preponderance of Trichinella species in Bulgaria. The research covered the period 2010-2016. Molecular analysis was performed with 120 Trichinella isolates. Two species were discovered: Trichinella britovi and Trichinella spiralis. T. britovi predominated over T. spiralis -113 isolates $(94.17 \%)$ and 7 (5.83\%) respectively. Both species were identified in domestic pigs and wild boars, with $T$. britovi:T.spiralis ratios in 45:1 in wild boars and 1:1 in domestic pigs. T. britovi was the geographically more widespread species. It was found in samples from domestic and wild animals from all over the country, while $T$. spiralis has only been found in several areas.
\end{abstract}

Key words: bear, badger, domestic pig, fox, jackal, Trichinella britovi, Trichinella spiralis, wild boar, wolf

\section{INTRODUCTION}

Trichinellosis is a foodborne disease that affects skeletal muscle tissue of wild and domestic carnivores and omnivores. The causative agents of this disease are nematodes belonging to the genus Trichinella, family Trichinellidae. By the middle of last century it was thought that the cause of trichinellosis in all animal species was the same - Trichinella spiralis. However, the implementation of molecular biology methods proved the existence of a significant diversity of species and differences in the taxonomy, the geographical dissemination and the epidemiology of trichinellosis (Pozio \& Zarlenga, 2005). According to FAO/WHO/OIE Guidelines 11 genotypes are identified in the genus Trichinella (Anonymous, 2007). Two main clades are recognised in the genus: the first that encapsulates in host muscle tissue and a second that does not. The representatives of eight genotypes have species names. The encapsulated clade includes 5 species: $T$. spiralis - genotype T1, T. nativa - genotype T2, T. britovi genotype T3, T. murrelli - genotype T5 and T. nelsoni - genotype $\mathrm{T} 7$ and three genotypes (Trichinella T6, T8 and T9), 
which invades mammals. The nonencapsulated (acapsular) clade includes three taxonomically distinct species: $T$. pseudospiralis - genotype T4, T. papuae - genotype T10 and T. zimbabwensis genotype T11. The first one invades mammals and birds and the other two species - mammals and reptiles. The existence of genotype T12 isolated from a cougar in Argentina is supposed (Krivokapich et al., 2008).

From epidemiological point of view there are two cycles of trichinellosis: synantropic (domestic) cycle where T. spiralis is usually involved and in rare cases $T$. britovi, as well as a sylvatic cycle specific for all Trichinella species and genotypes.

The most commonly spread etiological agents of trichinellosis in European wild and domestic animals are $T$. spiralis and $T$. britovi. Two other species $-T$. nativa and $T$. pseudospiralis are of minor importance as pathogens in domestic animals (Pozio, 2007). According to Pozio et al. (2009) T. britovi is more widespread in the Member States of the European Union and it can be found in $62.5 \%$ to $100 \%$ of the samples. T. spiralis is widespread in Finland, Germany, Poland and Spain $56.3 \%$ to $92.8 \%$ of the samples. In Romania, the ratio is $49.2 \%$ to $50.8 \%$ in favour of T. britovi. T. britovi is more widespread than $T$. spiralis in wild carnivores $-89 \%$ vs. $11 \%$ respectively. According to this research $T$. spiralis is more commonly found in wild boars (62\% vs. 38\%), domestic pigs $(82 \%$ vs. $18 \%)$ and rodents ( $75 \%$ vs. $25 \%$ respectively).

In Bulgaria, Kurdova et al. (2004) investigated parasite isolates obtained upon 15 epidemic outbreaks. Obtained results showed the predominance of $T$. britovi (etiological agent in 10 outbreaks) while T. spiralis was found in 5 outbreaks. The authors identified $T$. britovi in 4 wild boars and $T$. spiralis in only one sample from wild boar. Between 1995 and 2002, 18 human outbreaks have been recorded (Petkova et al., 2008). In seven of them the etiological agent was identified as $T$. spiralis and in 11 outbreaks as $T$. britovi. In wild boars the authors determined only $T$. britovi whereas in domestic pigs - both species.

The purpose of this research was to conduct a more extensive survey on species composition and distribution of agents of trichinellosis in domestic and in wild animals in our country.

\section{MATERIALS AND METHODS}

The research covered the period 2010 2016. The isolated larvae of Trichinella were detected during the routine official control of samples obtained from meat products, slaughtered domestic pigs, wild pigs and shot wild carnivores. The studies were carried out following the reference method of digestion using a magnetic stirrer according to Regulation (EU) 2015/ 1375. A total number of 120 isolates were typified and sorted as followed: 8 from domestic pigs, 92 from wild boars, 5 from foxes, 3 from jackals, 3 from wolves, 3 from badgers, 1 from a bear, 3 from raw dried sausage made of wild boar meat and 2 from minced meat (made of mixture of domestic pig meat, beef meat/horse meat). Trichinella spp. larvae were identified at the species level by multiplex PCR, which allowed differentiating the eight species of Trichinella and one of the genotypes - T6.

Ninety one Trichinella spp. isolates were tested in the European Union Reference Laboratory for Parasites (EURLP) in Italy according to the laboratory protocol (http://www.iss.it/binary/crlp/ cont/MI_02 _WEB_SITE_REV_6.pdf). 
Table 1. Species composition and distribution of causes of trichinosis in domestic and wild animals in Bulgaria in the period 2010-2016

\begin{tabular}{|c|c|c|c|}
\hline District & Hosts and sources & Isolates number & Species \\
\hline Blagoevgrad & Wild boar & 32 & Trichinella britovi \\
\hline \multirow[t]{2}{*}{ Burgas } & Wild boar & 2 & Trichinella britovi \\
\hline & Jackal & 1 & Trichinella britovi \\
\hline \multirow[t]{2}{*}{ Varna } & Wild boar & 1 & Trichinella britovi \\
\hline & Minced meat (pig+beef) & 1 & Trichinella spiralis \\
\hline Veliko Tarnovo & Wild boar & 3 & Trichinella britovi \\
\hline \multirow{2}{*}{ Vidin } & Wild boar & 2 & Trichinella britovi \\
\hline & Fox & 1 & Trichinella britovi \\
\hline Vratsa & Wild boar & 1 & Trichinella britovi \\
\hline \multirow[t]{2}{*}{ Gabrovo } & Wild boar & 8 & Trichinella britovi \\
\hline & Wild boar & 1 & Trichinella spiralis \\
\hline Dobrich & \multicolumn{3}{|c|}{ No isolates } \\
\hline Kardzhaly & Wild boar & 6 & Trichinella britovi \\
\hline Kyustendil & Wild boar & 3 & Trichinella britovi \\
\hline \multirow[t]{2}{*}{ Lovech } & Wild boar & 1 & Trichinella britovi \\
\hline & Wild boar & 1 & Trichinella spiralis \\
\hline Montana & Fox & 1 & Trichinella britovi \\
\hline \multirow[t]{2}{*}{ Pazardzhik } & Badger & 1 & Trichinella britovi \\
\hline & Fox & 1 & Trichinella britovi \\
\hline Pernik & Wild boar & 1 & Trichinella britovi \\
\hline Pleven & \multicolumn{3}{|c|}{ No isolates } \\
\hline \multirow[t]{2}{*}{ Plovdiv } & Wild boar & 3 & Trichinella britovi \\
\hline & Jackal & 1 & Trichinella britovi \\
\hline Razgrad & \multicolumn{3}{|c|}{ No isolates } \\
\hline Rousse & Wild boar & 1 & Trichinella britovi \\
\hline Sliven & Wild boar & 7 & Trichinella britovi \\
\hline \multirow[t]{3}{*}{ Smolyan } & Wild boar & 2 & Trichinella britovi \\
\hline & Wolf & 2 & Trichinella britovi \\
\hline & Fox & 1 & Trichinella britovi \\
\hline \multirow[t]{2}{*}{ Silistra } & Wild boar & 2 & Trichinella britovi \\
\hline & Fox & 1 & Trichinella britovi \\
\hline \multirow[t]{4}{*}{ Sofia-town } & Wild boar & 7 & Trichinella britovi \\
\hline & Domestic pig & 2 & Trichinella spiralis \\
\hline & Domestic pig & 2 & Trichinella britovi \\
\hline & Raw dried sausage & 2 & Trichinella britovi \\
\hline \multirow[t]{6}{*}{ Sofia-district } & Wild boar & 3 & Trichinella britovi \\
\hline & Domestic pig & 1 & Trichinella britovi \\
\hline & Domestic pig & 1 & Trichinella spiralis \\
\hline & Wolf & 1 & Trichinella britovi \\
\hline & Minced meat (pig+ horse) & 1 & Trichinella spiralis \\
\hline & Raw dried sausage & 1 & Trichinella britovi \\
\hline \multirow[t]{3}{*}{ Stara Zagora } & Wild boar & 2 & Trichinella britovi \\
\hline & Badger & 1 & Trichinella britovi \\
\hline & Bear & 1 & Trichinella britovi \\
\hline Targovishte & Wild boar & 1 & Trichinella britovi \\
\hline Haskovo & Wild boar & 2 & Trichinella britovi \\
\hline \multirow[t]{3}{*}{ Shumen } & Domestic pig (free ranging) & 2 & Trichinella britovi \\
\hline & Jackal & 1 & Trichinella britovi \\
\hline & Badger & 1 & Trichinella britovi \\
\hline Yambol & & No isolates & \\
\hline
\end{tabular}


Twenty-nine samples were tested in the National Reference Laboratory of Parasitic Zoonoses, Sofia (Lalkovski et al., 2011).

\section{RESULTS}

The results of the multiplex PCR for Trichinella spp. isolates identification are shown in Table 1.

Molecular analysis was performed with 120 larval isolates from 24 districts of the country. Two species were discovered: Trichinella britovi and Trichinella spiralis. T. britovi was found in 113 $(94.17 \%)$ and $T$. spiralis in $7(5.83 \%)$ samples. Both types were found in domestic pigs and wild boars. Concerning species prevalence, there was a predominance of T. britovi $(97.83 \%)$ in wild boars compared to $T$. spiralis $(2.17 \%)$. In domestic pigs the ratio T. britovi:T.spiralis was $1: 1$. In wild carnivores only $T$. britovi was found. T. britovi is the geographically mo- re widespread Trichinella species (Fig. 1) found in samples from domestic pigs, wild boars and wild carnivores from 24 districts of the country, while $T$. spiralis has been found in only 5 districts.

\section{DISCUSSION}

The above mentioned results showed that trichinellosis in domestic pigs, wild boars and wild carnivores in the country was caused by two Trichinella species $-T$. spiralis and T. britovi. According to Kurdova et al. (2004) the same two species caused human trichinellosis outbreaks. Our results confirm the opinion of Pozio et al. (2009), that in most countries of the European Union, including Bulgaria, $T$. britovi was the more prevalent species. $T$. spiralis was detected in meat and meat products in five backyard domestic pigs. Given that four of them originated from two adjacent districts (Sofia-town and

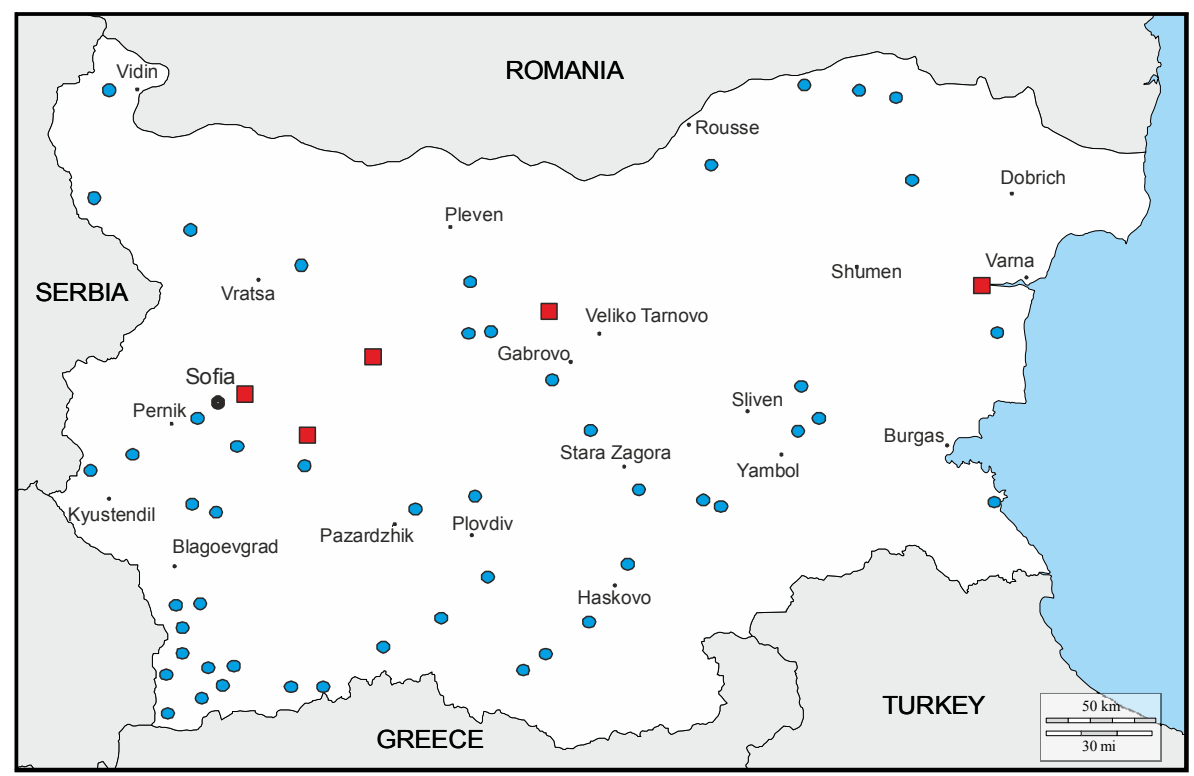

Fig. 1. Geographical distribution of Trichnella britovi and Trichnella spiralis in Bulgaria (2010-2016); • Trichinella britovi; - Trichinella spiralis 
Sofia-district) this region can be considered as a risk area. In the same districts Petkova et al. (2008) identified $T$. spiralis as etiological agent in 6 outbreaks during 2000-2001 and Rainova et al. (2016) reported 10 human outbreaks from 20082014. Unlike Petkova et al. (2008) we found $T$. spiralis in a wild boar which suggests that this species is not restricted only to domestic cycle of trichinellosis in our country. Two T. spiralis-infected wild boars were shot in the central north region of Bulgaria, where T. britovi-infected wild boars were also detected, but we didn't find a mixed Trichnella spp. infection as reported in Spain. However, most of $T$. britovi-infected wild boars were from southwestern region of Bulgaria, where Rainova et al. (2016) recorded most human outbreaks in the country. Our studies did not detect the non-encapsulated species Trichinella pseudospiralis reported by Michov et al. (2006).

The results of our research give us the reason to make the following important conclusions:

- A widespread species in the country was Trichnella britovi, which was the only etiologic agent of trichinellosis in wild carnivores in Bulgaria;

- The high extensity of invasion in foxes $-42.3 \%$ (Georgieva et al., 2000) plays an important role in a stable trend towards increase in the number of wild boars invaded by Trichinella spp.;

- The wild boars were the only reservoir of Trichnella spiralis in the sylvatic cycle of trichinellosis in Bulgaria;

- The high incidence and wide spread of Trichinella britovi in wild boars in Bulgaria posed a high risk for transmission into the domestic cycle, especially where free ranging pigs are in contact with wildlife reservoirs.

\section{ACKNOWLEDGEMENTS}

The author thanks Dr. Edoardo Pozio and Dr.Gianluca Marucci from EURLP, Italy for their help in Trichinella species identification by multiplex PCR.

\section{REFERENCES}

Anonymous, 2007. FAO/WHO/OIE. Guidelines for the surveillance, management, prevention and control of trichinellosis. http://www.trichinellosis.org/uploads/ FAO-WHO-OIE Guidelines.pdf (6 June 2017 date last accessed)

Georgieva, D., V. Koinarski, A. Ivanov, P. Prelesov \& Z. Kirkova, 2000. Role of wild carnivores in the epizootology and epidemiology of trichinellosis. Bulgarian Journal of Veterinary Medicine, 3, 199-204.

Krivokapich, S. J., C. L. Prous, G. M. Gatti, V. Confalonieri, V. Molina, H. Matarasso \& E. Guarnera, 2008. Molecular evidence for a novel encapsulated genotype of Trichinella from Patagonia, Argentina. Veterinary Parasitology, 156, 234-240.

Kurdova, R., N. Muller, N. Tsvetkova, L. Michov, D. Georgieva, M. Ivanova \& B. Gottstein, 2004. Characterisation of Trichinella isolates from Bulgaria by molecular typing and cross-breeding. Veterinary Parasitology, 123, 179-188.

Lalkovski, N., M. Bonovska, T. Savova \& Z. Petrova, 2011. Identification and differentiation of Trichinella sp. larvae by Multiplex PCR. In: Proceedings of the Anniversary Scientific Conference " 110 years NDRVMI", Sofia, 142-146.

Michov, L., M. Alexandrov, S. Lazarova, P. Petkova, N. Boiajiev, P. Kamenov, I. Lachev \& E. Pozio, 2006. First detection of Trichinella pseudospiralis in wild animals from Bulgaria. Veterinarna Sbirka, 1-2, 19-24 (BG).

Perez-Martın, J. E., F. J. Serrano, D. Reina, J. A. Mora \& I. Navarrete, 2000. Sylvatic trichinellosis in southwestern Spain. Journal of Wildlife Diseases, 36, 531-534. 
Petkova, S., L. Mihov, K. Vutova, I. Tsenov, G. La Rosa \& E. Pozio, 2008. Epidemiolegical and clinical patterns of trichinellosis in Bulgaria from 1995 to 2002. Parasite, 15, 86-88.

Pozio, E. \& D. S. Zarlenga, 2005. Recent advances on the taxonomy, systematics and epidemiology of Trichinella. International Journal of Parasitology, 35, 1191-1204.

Pozio, E., 2007. World distribution of Trichinella spp. infections in animals and humans. Veterinary Parasitology, 149, 3-21.

Pozio, E., L. Rinaldi, G. Marucci, V. Musella, F. Galati, G. Cringoli, P. Boireau \& G. La Rosa, 2009. Hosts and habitats of Trichinella spiralis and Trichinella britovi in Europe. International Journal for Parasitology, 39, 71-79.

Rainova, I., I. Kaftandjiev, R. Harizanov, N. Tsvetkova, D. Jordanova, I. Marinova, R. Kurdova, T. Kantardjiev \& N. Lalkovski, 2016. Outbreaks of human trichinellosis, still a challenge for the public health au- thorities in Bulgaria. Journal of Public Health, 24, 291-297.

Paper received 24.03.2017; accepted for publication 07.04.2017

\section{Correspondence:}

Dr. Nikolay Lalkovski

National Diagnostic and Research Veterinary Medical Institute

Bulgarian Food Safety Agency

15 Pencho Slaveikov blvd.,

1606Sofia, Bulgaria

e-mail: 1aleto72@abv.bg 